\title{
In vitro effects of conjugated linoleic acid (CLA) on inflammatory functions of bovine monocytes
}

\author{
G. Ávila, C. Catozzi, D. Pravettoni, G. Sala, P. Martino, G. Meroni, C. Lecchi, and F. Ceciliani* \\ Department of Veterinary Medicine, Università Degli Studi di Milano, 26900, Milano, Italy
}

\section{ABSTRACT}

The conjugated linoleic acid (CLA) isomers, a group of naturally occurring isomers of the essential fatty acid (FA) linoleic acid, have received special attention in animal and human nutrition. Although they have long been used as dietary integrators in dairy cows, the effects of CLA isomers on bovine immune cells remain mostly undisclosed. The present study aimed to cover this gap and investigate the in vitro effects of CLA on inflammatory functions, including chemotaxis, phagocytosis, killing capability, and extracellular respiratory burst of purified bovine monocytes $\left(\mathrm{CD} 14^{+}\right)$. The apoptosis rate of monocytes was addressed as well. Once assessed, the effects of different concentrations $(10,50,100$, and $500 \mu M)$ of the 2 main CLA isomers, namely cis-9,trans-11 and trans-10,cis-12, the experiments were carried out using a concentration of $50 \mu M$ of the CLA isomers, both individually and in a mixture (50:50). The immunomodulatory activities of linoleic acid, an essential FA, and stearic acid, a saturated FA, were also investigated. Only the 50:50 CLA mixture was able to reduce monocyte apoptosis and to increase the extracellular respiratory burst during experimental proinflammatory conditions, as assessed by measuring production of reactive oxygen species. Linoleic acid and CLA had no effects on chemotaxis, phagocytosis, or killing capability. Remarkably, treatment of monocytes with stearic acid significantly reduced their chemotactic capability. The present results demonstrated that CLA isomers do have immunomodulatory effects on some functions of bovine monocytes, and that the mixture of the 2 CLA isomers is more effective than the CLA isomers individually.

Key words: conjugated linoleic acid, monocyte, innate immunity, dairy cow

Received April 6, 2020.

Accepted May 4, 2020.

*Corresponding author: fabrizio.ceciliani@unimi.it

\section{INTRODUCTION}

Conjugated linoleic acid is a group of naturally occurring positional and geometrical isomers of the essential n-6 fatty acid (FA) linoleic acid, featuring conjugated double bonds in either cis or trans configuration (Bhattacharya et al., 2006). Conjugated linoleic acid is synthesized as an intermediate product during the biohydrogenation of linoleic acid by Butyrivibrio fibrosolvens rumen bacteria (Churruca et al., 2009) or through the endogenous conversion of trans-vaccenic acid by desaturase- 9 in the mammary gland, as previously demonstrated (Griinari et al., 2000).

Among the 28 CLA isomers thus far reported, the cis9,trans-11 (c9,t11) and the trans-10,cis-12 (t10,c12) are the most abundant and the ones that show relevant biological activities (Pariza et al., 2001; Viladomiu et al., 2016). Conjugated linoleic acid is formed in ruminants, in particular the $\mathrm{c} 9, \mathrm{t} 11$ isomer that is the most predominant isomer in milk fat (80 to $90 \%$ ). The concentration of CLA in blood has been recently measured as $0.54 \mathrm{mg} / \mathrm{L}$, primarily c9,t11-18:2 (Lahlou et al., 2014) The c9,t11 isomer concentration in the milk fat of multiparous late-lactation Holstein-Friesian cows is $0.71 \mathrm{~g} / 100 \mathrm{~g}$ of total FA, and $0.02 \mathrm{~g} / 100 \mathrm{~g}$ of blood fat, and it increases significantly $(P<0.01)$ up to 2.5 -fold after feeding with fresh pasture (Kay et al., 2005). In other studies, the mean concentration of the c9,t11 isomer in bovine milk varied from 5.04 to $11.28 \mathrm{mg} / \mathrm{g}$ of fat in animals fed with different diets, showing that CLA milk content is markedly influenced by the composition of the animal's diet (Bauman et al., 1999; Fritsche et al., 1999). The 2 isomers differ in their biological effects, and, furthermore, different activities were demonstrated when they were combined in equal amounts (Pariza et al., 2001). Dietary supplementation of dairy cows with CLA is a frequent and relevant nutrition strategy, as in vivo studies have demonstrated reduction in milk fat and glucose production, allowing more efficient wholebody energy utilization and enhanced milk yield (Selberg et al., 2004; Dänicke et al., 2012; Galamb et al., 2017). Besides the effects on metabolism, supplementing CLA as well as other PUFA in dairy ruminants has 
been identified as a potential strategy to mitigate the effects of the proinflammatory status associated with the oxidative stress related to metabolic and endocrine changes around calving in dairy cows (Sordillo, 2016). Although CLA isomers have been extensively used for improving milk quality and alleviating the magnitude of negative energy balance, the information about their influence on cows' immunity is limited. In vitro studies carried out on a model of mammary gland epithelial cells (BME-UV1) have demonstrated that CLA can modulate inflammation and respiratory burst (Basiricò et al., 2015, 2017; Dipasquale et al., 2018). The effects of CLA on the activity of immune cells have been investigated in bovine peripheral blood mononuclear cells (PBMC) and resulted in contradictory results. Supplementing dams with a commercial CLA preparation (Lutrell Pure, BASF SE, Ludwigshafen, Germany) in the preceding lactation period exerted effects on the ex vivo stimulation ability of bovine PBMC (Dänicke et al., 2012). In an in vitro study assessing the effect of c9,t11 and t10,c12 CLA isomers, the inhibition of bovine isolated PBMC mitogen-activated proliferation was detected, together with a marginal effect of c9,t11 isomer on cells' cytokine expression pattern (Renner et al., 2013). The apparent inconsistency of these results may be related to the fact that most of the studies were not carried out with comparable experimental designs and on an isolated population, but on PBMC, which included both lymphocytes and monocytes. Monocytes are myeloid cells derived from bone marrow. They play a pivotal role in immune defense against infections and injuries and are involved in almost all phases of the immune reaction (Hussen and Schuberth, 2017). Given their pivotal role, the present study aimed to investigate the in vitro effect of c9,t11 and t10,c12-CLA isomers, both individually and using a mixture (50:50) of the 2 isomers, on a sorted bovine monocyte population. To examine whether and how these CLA isomers could play a role in modulating monocytes' inflammatory activities, their effects on chemotaxis, respiratory burst, phagocytosis, killing capability, and apoptosis were evaluated. The effects of other unsaturated FA (linoleic acid) and saturated FA (stearic acid), were assessed as well.

\section{MATERIALS AND METHODS}

\section{Materials}

Ficoll-Paque Plus (GE Healthcare Bio-Sciences AB, Uppsala, Sweden), EDTA $2 \mathrm{~m} M$, red blood cell lysis buffer, and sterile-filtered Dulbecco's PBS without calcium and magnesium (Sigma-Aldrich, St. Louis, MO) were used for bovine PBMC isolation. For monocyte purification, we used CD14 MicroBeads, LS (large size) columns, and 30-mm pre-separation filters (MiltenyiBiotech, Bergisch Gladbach, Germany) and BSA (Sigma-Aldrich). After isolation, cells were resuspended in complete medium, comprising RPMI 1640 medium with $25 \mathrm{~m} M$ HEPES and L-glutamine supplemented with $1 \%$ nonessential amino acid solution $100 \times$ and $1 \%$ penicillin streptomycin solution $100 \times$ (Euroclone, Milano, Italy), and $10 \%$ fetal bovine serum (Sigma-Aldrich). Sterile 96-well Microtest plates (Becton Dickinson and Company, Franklin Lakes, NJ), 384-well black plates, 24-well Transwell migration plates (Costar, Corning Inc., Corning, NY), and cryogenic vials (Sigma-Aldrich) were used for cell culture. The FA 9(E),11(Z)octadecadienoic acid and 10(E),12(Z)-octadecadienoic acid (c9,t11 and t10,c12 CLA, respectively; Matreya LLC, State College, PA) and linoleic and stearic acid (Sigma-Aldrich) were used for cell treatment.

Zymosan A from Saccharomyces cerevisiae and cytochrome $\mathrm{C}$ from equine heart, phorbol myristate acetate (PMA; Sigma-Aldrich), fluorescein-labeled Escherichia coli K-12 strain bioparticles (Invitrogen, Carlsbad, CA), and E. coli ATCC 25922 (strain Seattle 1946; LCG Standards Ltd., Teddington, UK) were used for chemotaxis, reactive oxygen species (ROS) production, phagocytosis, and killing capability assays, respectively.

\section{Purification of Monocytes from Blood}

Peripheral blood from 33 healthy pluriparous latelactation Holstein-Friesian cows was collected during routine slaughtering procedures at a local slaughterhouse, in sterile flasks containing $1.8 \mathrm{mg} \mathrm{K} \mathrm{K}_{2}$ EDTA per $\mathrm{mL}$ of blood as anticoagulant. Monocytes (CD14 ${ }^{+}$cells) were isolated through Ficoll $1.077 \mathrm{~g} / \mathrm{mL}$ density gradient centrifugation, as previously described (Dilda et al., 2012), with a few modifications. Briefly, blood was first centrifuged at $1,260 \times g$ for $30 \mathrm{~min}$ at $4^{\circ} \mathrm{C}$, and the buffy coat (PBMC ring) was collected. The PBMC were then diluted 1:5 in sterile cold PBS without $\mathrm{Ca}^{2+}$ and $\mathrm{Mg}^{2+}$, containing $2 \mathrm{mM}$ EDTA, layered on Ficoll, and centrifuged without breaks at 1,700 $\times g$ for $30 \mathrm{~min}$ at $4^{\circ} \mathrm{C}$. The PBMC were recovered at the interface, washed with PBS without $\mathrm{Ca}^{2+}$ and $\mathrm{Mg}^{2+}$, and treated with red blood cell lysis buffer for red blood cell elimination. Two subsequent centrifugations $(500 \times g$ for 7 min with cold PBS without $\mathrm{Ca}^{2+}$ and $\mathrm{Mg}^{2+}$, with 2 $\mathrm{m} M$ EDTA) were carried out to remove platelets. The $\mathrm{CD} 14^{+}$monocyte purification was carried out using the magnetic-activated cell sorting technique. Isolated PBMC were incubated with anti-human CD14 microbeads for $15 \mathrm{~min}$ at $4^{\circ} \mathrm{C}$, and $\mathrm{CD} 14^{+}$cells were isolated 
from a LS (large size) column, using a MD (MidiMACS) separator, according to the manufacturer's instructions. The homogeneity of the sorted cells $(>98 \%)$ was determined using an automatic cell counter (Sysmex Corp., Kobe, Japan). The working concentration of monocytes was then adjusted with complete medium.

\section{Unsaturated and Saturated FA Preparation}

Stock solutions of unsaturated and saturated FA were prepared. The 2 CLA isomers (c9,t11 and t10,c12 CLA), linoleic acid, and stearic acid were reconstituted in ethanol at concentrations of $357 \mathrm{~m} M$ for CLA isomers and linoleic acid and $70.3 \mathrm{mM}$ for stearic acid. Stock solutions were stored at $-20^{\circ} \mathrm{C}$, and fresh dilutions with the complete medium were prepared when needed. The amounts of CLA isomers used for preliminary studies ranged from 0 to $500 \mu M$. The authors only used one mixture containing both CLA isomers in a 50:50 proportion at a final concentration of $50 \mu \mathrm{M}$. The rest of the fatty acids (linoleic acid and stearic) were prepared individually in aqueous solutions (medium) at final concentration of $50 \mu \mathrm{M}$. During the first part of the study, the working concentration of CLA isomers was determined by testing the different concentration of individual c9,t11 and t10,c12 CLA isomers on monocyte apoptosis. Once the CLA working solution was determined, it was tested on monocyte immune-related functions, including chemotaxis, phagocytosis, respiratory burst, killing capability, and apoptosis.

\section{Apoptosis Assay}

Apoptosis assay was performed in triplicate on $50 \times$ $10^{3}$ sorted monocytes seeded in 384-well black plates. The experiment was carried out on cells purified from 8 animals. First, to determine the CLA working concentration, the cells were incubated overnight at $39^{\circ} \mathrm{C}$ in a humified atmosphere of $5 \% \mathrm{CO}_{2}$, with increasing concentrations of c9,t11 and t10,c12 CLA isomers (10, 50,100 , and $500 \mu M$ ) or with $0.1 \%$ ethanol as control (vehicle), this being the concentration of ethanol found in $500 \mu M$ of CLA isomers. At this concentration of ethanol, no effects on viability on bovine PBMC were observed, as assessed by a 3-[4,5-dimethylthiazol2-yl]-2,5-diphenyl-tetra-zolium bromide (MTT)-based assay (data not shown). Once the CLA working concentration was determined $(50 \mu M)$, the effects of other unsaturated and saturated FA on apoptosis of monocytes were measured by incubating the cells with $50 \mu M$ of each CLA isomer, the 50:50 mixture of the 2 isomers, linoleic acid, stearic acid, and ethanol (vehicle) as the control, with the same concentration of ethanol found in the $50 \mu M \mathrm{FA}$ solutions $(0.014 \%)$. The apop- tosis rate was measured after overnight incubation, using the Apo-ONE Homogeneous Caspase-3/7 kit (Promega, Madison, WI). The caspase- $3 / 7$ reagent was added to each well, and the fluorescence intensity was measured using a fluorescence plate reader Fluoroscan Ascent (Thermo Fisher Scientific Oy Ratastie, Vantaa, Finland) at 485/538 nm (absorbance/emission) every 30 min up to $4 \mathrm{~h}$, as previously described for bovine monocytes (Ceciliani et al., 2007).

\section{Chemotaxis Assay}

Monocyte chemotaxis toward zymosan-activated serum (ZAS) was measured as previously reported (Lecchi et al., 2008; McClelland et al., 2010) with some minor modifications. The experiment was carried out on cells purified from 8 animals. Monocytes were first pretreated overnight, in absence of chemoattractant, with $50 \mu M$ of each CLA isomer, the 50:50 mixture of the 2 isomers, linoleic acid, stearic acid, or $0.014 \%$ ethanol as the control, in 24-well Transwell migration plates (Corning Inc.), equipped with a $5-\mu \mathrm{m}$ pore size membrane. A total of $1 \times 10^{5}$ monocytes $(100 \mu \mathrm{L}$ final volume) were added in triplicate in the upper chamber, and FA and migration medium (RPMI 1640 with $1 \%$ fetal bovine serum) were added in both chambers to a final volume of $750 \mu \mathrm{L}$. Cells were incubated overnight at $39^{\circ} \mathrm{C}$ in a humified atmosphere of $5 \% \mathrm{CO}_{2}$. After pretreating the cells, chemotaxis was measured by adding $3 \mathrm{mg} / \mathrm{mL}$ of the chemoattractant ZAS to the lower chamber, in the presence of newly added FA $(50 \mu M)$ or ethanol (vehicle) as control, and again incubating for $2 \mathrm{~h}$ at $39^{\circ} \mathrm{C}$ in a humified atmosphere of $5 \% \mathrm{CO}_{2}$. For the negative control, cells were incubated with the vehicle without ZAS. Finally, the upper chambers were removed, nonmigrated cells on the upper part of the membrane were gently eliminated using a swab moistened with PBS, and migrated cells were stained with Diff-Quick (Sigma-Aldrich) and counted in 10 different fields, using light microscopy.

\section{Determination of Respiratory Burst by Measuring ROS Production Under Normal and Proinflammatory Conditions}

The production of extracellular superoxide anion $\left(\mathrm{O}_{2}{ }^{-}\right)$was determined using the cytochrome $\mathrm{C}$ reduction method, as previously described (Lecchi et al., 2016). The experiment was carried out on cells purified from 8 animals. A total of $1 \times 10^{5}$ monocytes $(50 \mu \mathrm{L})$ were seeded in complete RPMI 1640 medium without phenol red, in duplicates, in 96-well sterile plates. Cells were then incubated overnight at $39^{\circ} \mathrm{C}$ in a humidified atmosphere of $5 \% \mathrm{CO}_{2}$, with $50 \mu M(50 \mu \mathrm{L})$ of each 
CLA isomer individually, the 50:50 mixture of isomers, linoleic acid, stearic acid, or $0.014 \%$ ethanol (vehicle) as control at a final volume of $100 \mu \mathrm{L}$. At the end of the incubation time, $10 \mu \mathrm{L}$ of cytochrome $\mathrm{C}$ and 90 $\mu \mathrm{L}$ of Hanks' balanced salt solution (HBSS) or 100 $\mu \mathrm{L}$ of HBSS alone, as negative control, were added to each well to make up a final volume of $200 \mu \mathrm{L}$. Finally, to mimic possible proinflammatory conditions, the second set of experiments was performed by adding PMA $(2.5 \mu \mathrm{g} / \mathrm{mL}$ final concentration). The absorbance was measured every $30 \mathrm{~min}$ for $4 \mathrm{~h}$ at $550 \mathrm{~nm}$ with a LabSystems Multiskan plate reader spectrophotometer (LabX, Midland, Canada).

\section{Phagocytosis Assay}

Monocytes' phagocytic activity was determined as previously described (Lecchi et al., 2011). The experiment was carried out on cells purified from 9 animals. First, $6 \times 10^{8}$ fluorescein-labeled E. coli bioparticles (K-12 strain) were opsonized, by incubating them with $20 \%$ autologous serum for $30 \mathrm{~min}$ at $37^{\circ} \mathrm{C}$. The suspension was then centrifuged at $800 \times g$ for $15 \mathrm{~min}$ and suspended in HBSS. Opsonized bacteria were stored at $-20^{\circ} \mathrm{C}$ upon use. A $100-\mu \mathrm{L}$ suspension containing $3 \times 10^{5}$ monocytes was seeded in duplicates in 96-well sterile plates with $50 \mu M(50 \mu \mathrm{L})$ of each CLA isomer individually, the 50:50 mixture, linoleic acid, stearic acid, or $0.014 \%$ ethanol (vehicle) as the control. The medium was then added, to a final volume of $200 \mu \mathrm{L}$. Afterward, cells were incubated overnight at $39^{\circ} \mathrm{C}$ in a humidified atmosphere of $5 \% \mathrm{CO}_{2}$. Cells were then washed with sterile HBSS, and 45 opsonized fluorescein-labeled E. coli bioparticles $(100 \mu \mathrm{L})$ per cell were added. Monocytes were then incubated again for $2 \mathrm{~h}$ at $39^{\circ} \mathrm{C}$ in a humidified atmosphere of $5 \% \mathrm{CO}_{2}$. Cells were washed twice with HBSS, and $0.4 \%$ trypan blue was added to quench the fluorescence from noninternalized bacteria. Finally, cells were again washed with HBSS, and the fluorescence intensity of fluorescein-labeled $E$. coli bioparticles was measured using a Fluoroscan Ascent FL (Thermo Fisher Scientific, Waltham, MA) at 485/538 nm (absorbance/emission).

\section{Killing Capability Assay}

The intracellular bacteria-killing capability of monocytes was evaluated according to Lecchi et al. (2013). The experiment was carried out on cells purified from 7 animals. Briefly, E. coli ATCC 25922 (LCG Standards) was opsonized with $20 \%$ bovine serum at $37^{\circ} \mathrm{C}$ for 30 min. The bacteria were washed twice by centrifuging at $1,500 \times g$ for $10 \mathrm{~min}$ and suspended in sterile HBSS. A total of $3 \times 10^{5}$ bovine monocytes $(100 \mu \mathrm{L})$ were suspended in complete medium-containing cryogenic vials (300 $\mu$ L final volume; Sigma-Aldrich) and treated overnight with $50 \mu M(50 \mu \mathrm{L})$ of each CLA isomer individually, the 50:50 mixture of isomers, linoleic acid, stearic acid, or $0.014 \%$ ethanol as vehicle, at $39^{\circ} \mathrm{C}$ in a humidified atmosphere of $5 \% \mathrm{CO}_{2}$. Cells were then washed and incubated with $1 \times 10^{7}$ opsonized live $E$. coli and incubated for $1 \mathrm{~h}$ at $39^{\circ} \mathrm{C}$ in a humidified atmosphere of $5 \% \mathrm{CO}_{2}$. Monocytes were centrifuged at $110 \times g$ for 5 min to remove unbound bacteria and treated further for $1 \mathrm{~h}$ with $100 \mu \mathrm{g} / \mathrm{mL}$ of gentamicin to kill any remaining extracellular bacteria. Gentamicin was eliminated by washing with HBSS and centrifuging the cells at $110 \times g$ for 5 min. Finally, cells were lysed using $0.5 \%$ Triton X-100 (Sigma-Aldrich) for $10 \mathrm{~min}$, and the surviving E. coli were counted on MacConkey agar plates. Results are expressed in colony-forming units.

\section{Statistical Analysis}

Statistical analyses were performed in GraphPad Prism 8.0.2 (San Diego, CA). For the data normality assessment, the Shapiro-Wilk test was applied. Repeated measures 1-way ANOVA and Tukey's multiple comparison test were used to evaluate ROS production, under normal and proinflammatory conditions, in normally distributed data. Repeated measures Friedman test and Dunn's multiple comparison test were used for apoptosis, chemotaxis, phagocytosis, and killing capability, in non-normally distributed samples. Statistical differences were accepted at $P \leq 0.05$.

\section{RESULTS}

\section{Effects of c9,t11 and t10,c12 CLA Isomers on Bovine Monocyte Apoptosis}

To determine optimal concentrations of c9,t11 and t10,c12 CLA isomers, a preliminary study on monocytes was carried out by incubating the cells overnight with increasing concentrations of CLA isomers (10, 50, 100 , and $500 \mu M$ ) or with the vehicle (ethanol), and assessing their apoptosis rates (Supplemental Figure S1; https://doi.org/10.3168/jds.2020-18659). No effects were observed with any of the CLA isomers at increasing concentrations on the sorted population. The following experiments were then carried out using a concentration of $50 \mu \mathrm{M}$.

In the second part of the study, the differential effects of additional unsaturated (linoleic acid and the 50:50 mixture of both CLA isomers) and saturated FA (stearic acid) on monocyte apoptosis were compared. Compared with the vehicle (ethanol), after exposing 


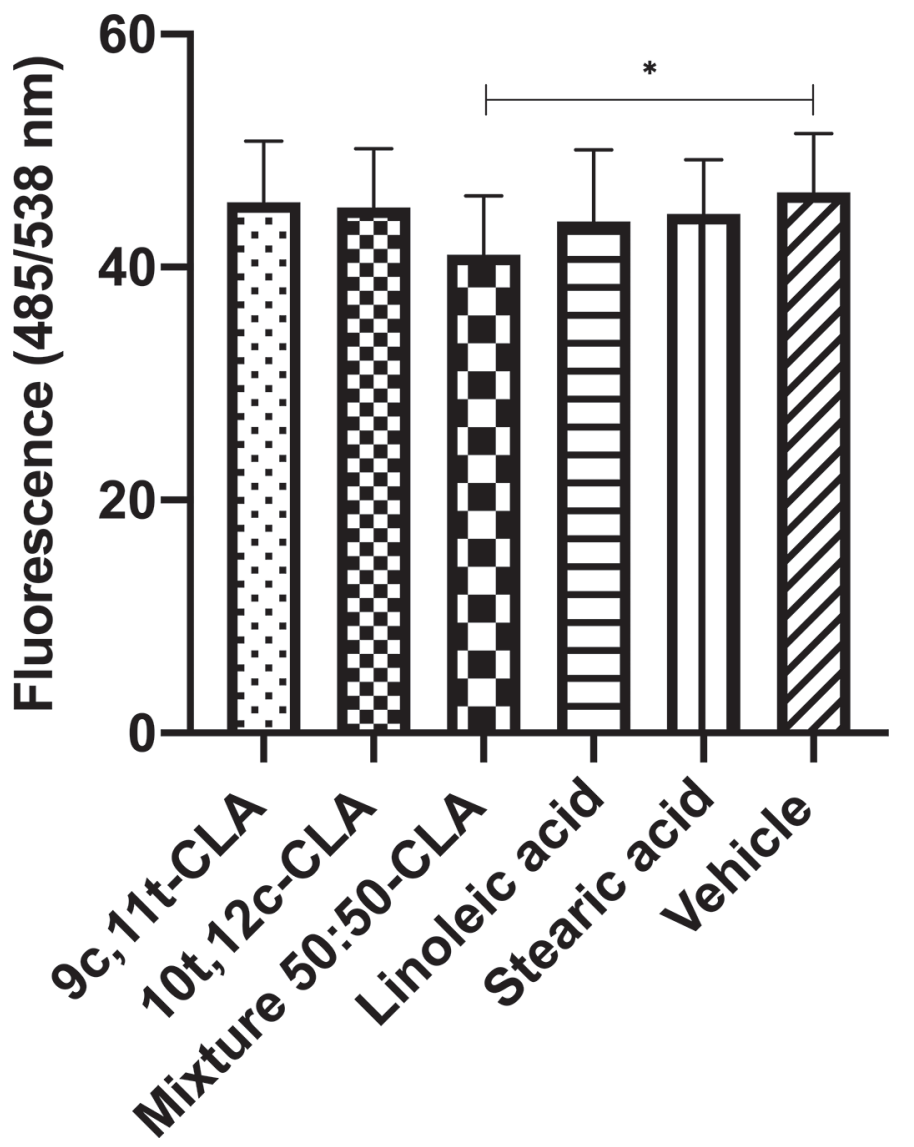

Figure 1. In vitro effect of saturated and unsaturated fatty acids on bovine monocytes apoptosis. Caspase- $3 / 7$ enzymatic activity of bovine monocytes after overnight incubation with fatty acids or vehicle $(0.014 \%$ ethanol). CLA isomers: $9 \mathrm{c}, 11 \mathrm{t}=$ cis-9,trans $-11 ; 10 \mathrm{t}, 12 \mathrm{c}=$ trans-10,cis-12. Data are means \pm SEM of 8 independent experiments. Significance was declared at $P<0.05(*)$.

the cells with the FA overnight, apoptosis (Figure 1) was found to be reduced $(P=0.013)$ only by the $50: 50$ mixture of CLA isomers.

\section{Effects of Unsaturated and Saturated FA on Bovine Monocyte Chemotaxis}

In this part of the study, the capabilities of unsaturated and saturated FA in modulating monocyte chemotactic activity were measured by using transwell migration plates. The chemotactic activity of monocytes was activated using ZAS, after exposing purified cells to $50 \mu M$ of FA or the vehicle (ethanol) overnight. The results are presented in Figure 2. Co-incubation with CLA and linoleic acid did not modulate monocyte chemotaxis. On the contrary, stearic acid induced an evident decrease in the chemotactic ability of monocytes in a statistically significant way $(P=0.032)$ compared with the control (vehicle), the 50:50 mixture of CLA ( $P$

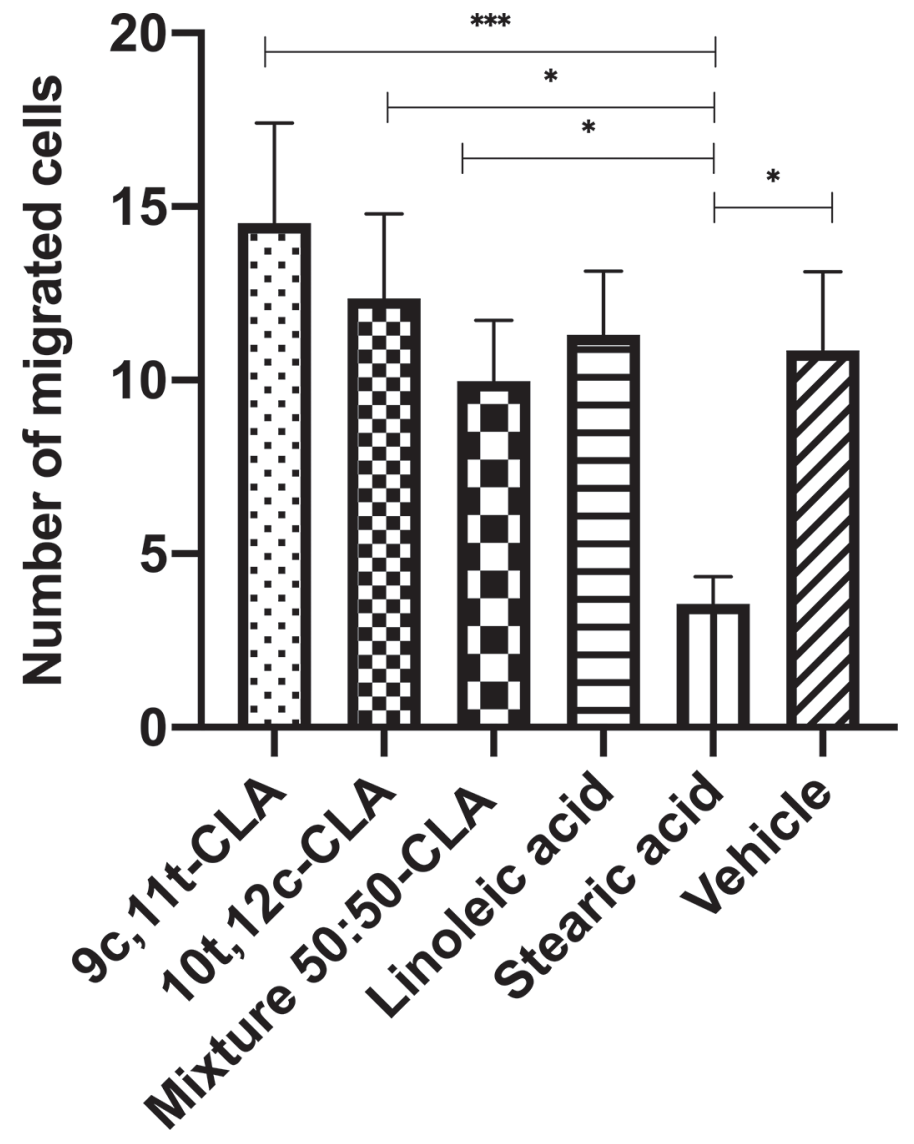

Figure 2. Differential effects of saturated and unsaturated fatty acids on bovine monocytes chemotaxis. Cells were treated with $0.014 \%$ ethanol as vehicle control. CLA isomers: 9c,11t $=$ cis-9,trans-11; $10 \mathrm{t}, 12 \mathrm{c}=$ trans-10,cis-12. Data are means \pm SEM of 8 independent experiments. Significance was declared at $P<0.05(*)$ and $P<0.001$ $(* * *)$.

$=0.049)$ and t10,c12 CLA $(P=0.013)$ and $(P<0.001)$ with c9,t11 CLA.

\section{Effects of Unsaturated and Saturated FA on Bovine Monocyte ROS Production}

Monocytes' production of extracellular superoxide anion under both normal and inflammatory conditions was evaluated through the cytochrome $\mathrm{C}$ reduction method. Cells were treated overnight with the FA, and then the ROS production was measured every 30 min for $4 \mathrm{~h}$ (Supplemental Figure S2; https://doi.org/10 .3168/jds.2020-18659). Because the highest ROS levels were observed 60 min after the addition of cytochrome C under both experimental conditions, the effects of the different FA on cells' superoxide anion production were further evaluated and presented only at this time point (Figure 3). Cells under normal conditions did not show any difference in ROS production (Figure 3A) 

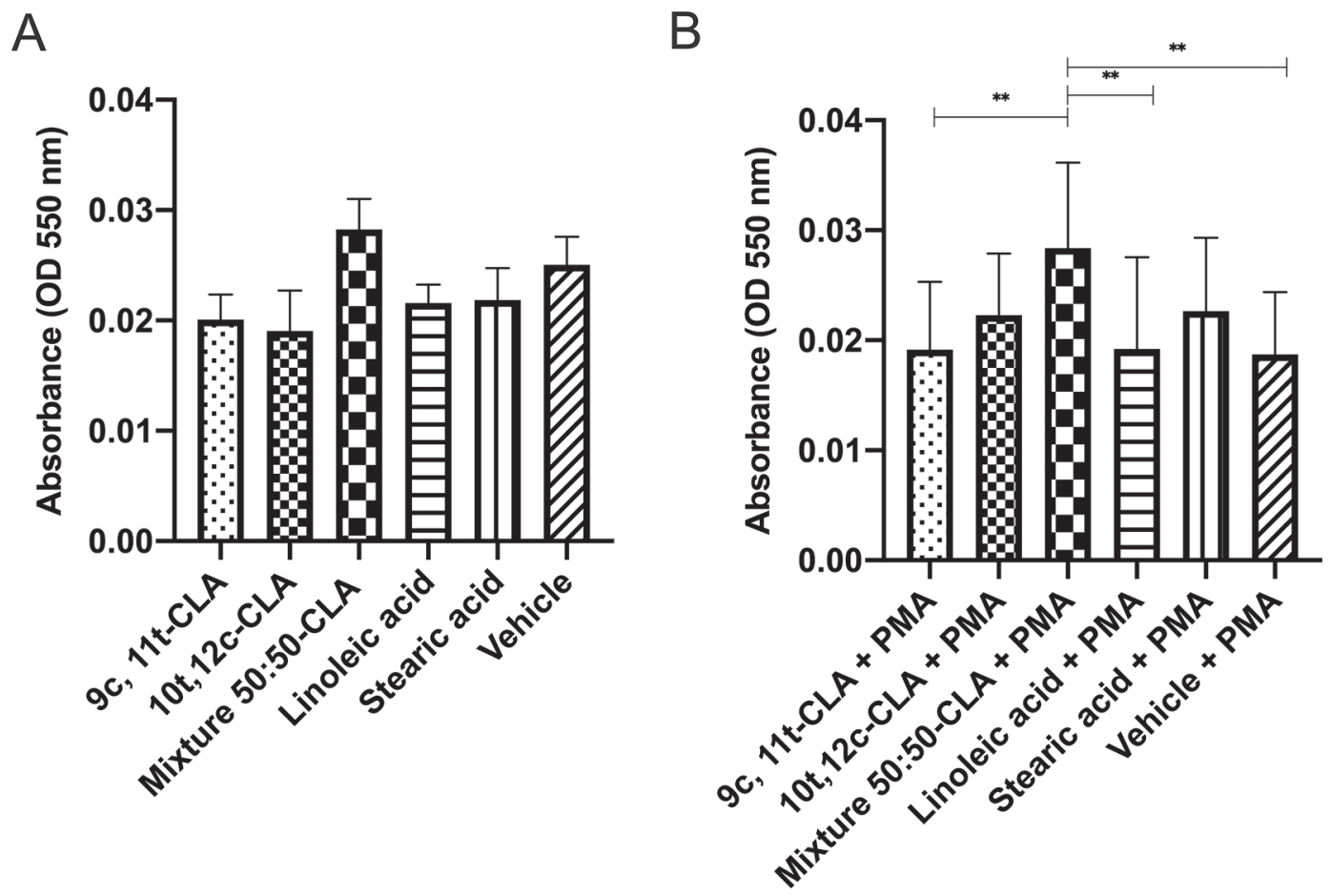

Figure 3. In vitro effects of saturated and unsaturated fatty acids on bovine monocyte extracellular superoxide anion generation, at 60 min after the addition of cytochrome C, under (A) normal conditions or (B) proinflammatory conditions [phorbol myristate acetate (PMA) stimulation]. Cells treated with $0.014 \%$ of ethanol (vehicle) were considered as control. CLA isomers: 9c,11t $=$ cis-9, trans-11; 10t,12c $=$ trans-10, cis-12 Data are means \pm SEM of 8 independent experiments. Significance was declared at $P<0.01(* *)$. OD $=$ optical density.

compared with control. On the contrary, an increase with the 50:50 mixture of CLA isomers was detected ( $P$ $=0.002$ ), after inducing a proinflammatory challenge with PMA (Figure 3B), compared with the control and $(P=0.003)$ with c9,t11 CLA and linoleic acid.

\section{Effects of Unsaturated and Saturated FA on Bovine Monocyte Phagocytosis and Killing Capability of E. coli}

The last set of experiments was aimed at studying whether co-incubation of isolated bovine monocytes with unsaturated and saturated FA affects their phagocytic and killing capabilities, as determined by fluorescein-labeled E. coli bioparticle internalization assay and intracellular E. coli killing assay, respectively. The capacity of monocytes to phagocytose (Figure 4A) and kill live E. coli (Figure 4B) when treated overnight with saturated and unsaturated FA was not affected compared with the vehicle.

\section{DISCUSSION}

In this study, we reported the effects of c9,t11 and t10,c12 CLA isomers, separately and as a 50:50 mix- ture, as well of the essential FA linoleic acid, and the saturated FA stearic acid, on several immunoregulatory functions of bovine monocytes $\left(\mathrm{CD} 14^{+}\right)$, including apoptosis, chemotaxis, phagocytosis, respiratory burst, and killing capability. Our main finding was that the 50:50 mixture of the c9,t11 and t10,c12 CLA isomers, when used at a concentration of $50 \mu M$, reduced the apoptosis rate of monocytes. Co-incubating cells with the 50:50 mixture of the 2 isomers also increased the respiratory burst, as determined by an increase of the production of ROS, but only in an experimental proinflammatory environment. On the contrary, CLA does not affect any of the other monocyte immunoregulatory functions herein assessed. Remarkably, we found that stearic acid was capable of a statistically significant reduction of chemotaxis.

Conjugated linoleic acid isomers have been routinely used as a feed supplement for dairy cows due to their beneficial in vivo effects. A decrease in milk fat synthesis and its consequent improvement in energy balance, increase in milk production, improved reproductive performance, and reduction of metabolic-related diseases have been reported (Perfield et al., 2007; de Veth et al., 2009; Basiricò et al., 2017; Csillik et al., 2017). However, their effects on bovine immunity have scarcely been addressed. 
A

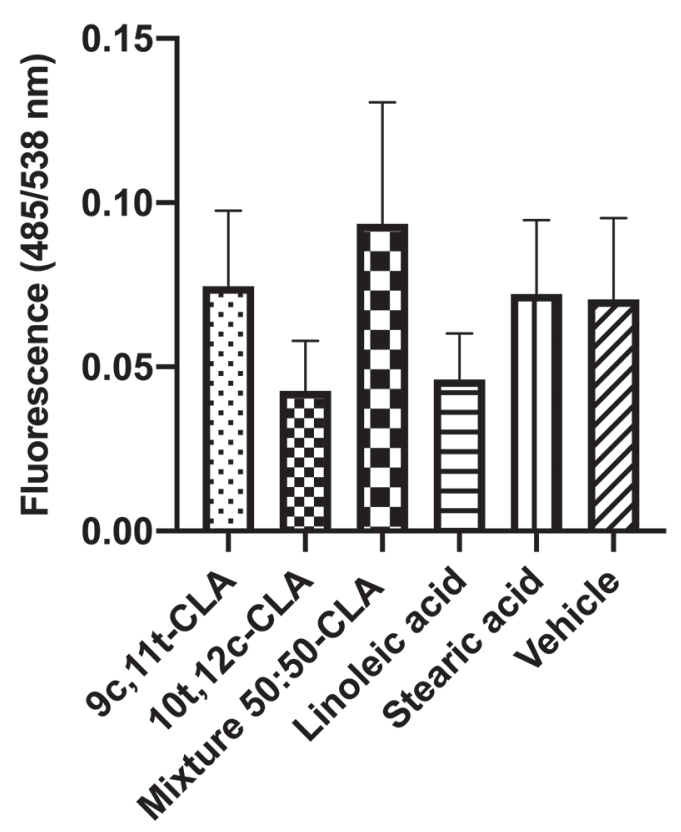

B

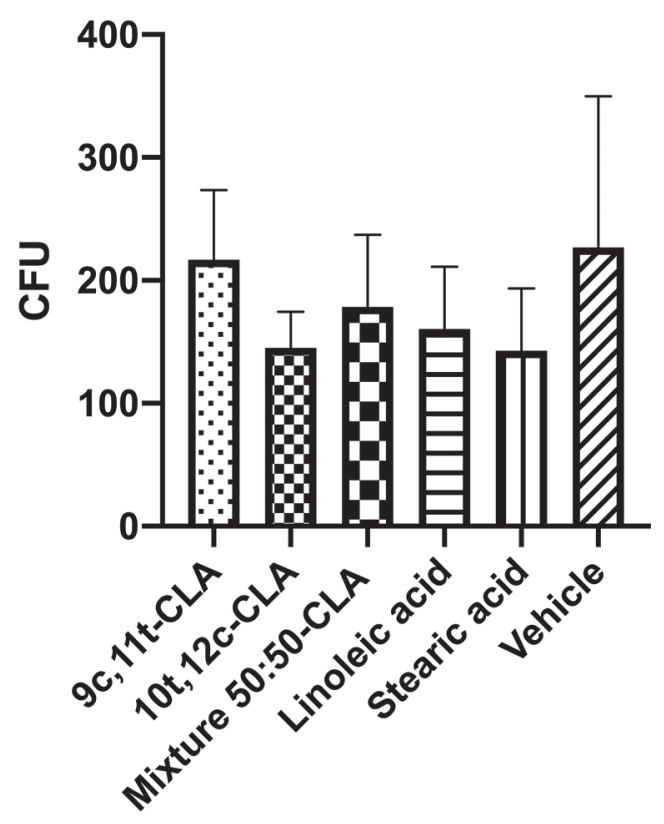

Figure 4. (A) Phagocytosis of fluorescein-labeled Escherichia coli bioparticles and (B) killing capability of live E. coli by bovine monocytes after overnight exposure to fatty acid. The results are expressed as fluorescence intensity (optical density at 485 to $538 \mathrm{~nm}$ ) and as colonyforming units (cfu), respectively. Cells treated with $0.014 \%$ ethanol (vehicle) were considered as control. CLA isomers: $9 \mathrm{c}, 11 \mathrm{t}=$ cis-9,trans-11; $10 \mathrm{t}, 12 \mathrm{c}=$ trans-10, cis-12. Data are means \pm SEM of 9 and 7 independent experiments, respectively.

Monocytes provide a suitable in vitro model to assess the influence of CLA on bovine immunity. Monocytes are circulating blood leucocytes that play a major role in host immune defense against invading pathogens (Chávez-Galán et al., 2015). They fulfill their defensive roles by migrating into inflamed tissues, producing proinflammatory cytokines and ROS, and eventually phagocytosing and killing engulfed pathogens. The adequate display of their functions is critical for an effective immune response.

The rate of apoptosis is regarded as a way to control the activity of blood monocytes, by either increasing or reducing their presence and activity in the inflammatory environment. Therefore, apoptosis is regarded as an integral feature of the immune system (Feig and Peter, 2007). Under this premise, this study tested whether CLA isomers affect apoptosis in sorted monocytes, demonstrating that a 50:50 mixture of the 2 CLA isomers can reduce apoptosis. The effects of CLA on apoptosis have been widely studied in cancer cell models in humans, and the results converge toward a pro-apoptotic and antiproliferative effect (Ochoa et al., 2004; Wang et al., 2008). Studies carried out on bovine cellular models have yielded apparently contradictory results. In bovine mammary cells (MAC-T cell line), co-incubating with $35 \mu M$ concentrations of both CLA isomers promoted an increase of apoptosis rate (Keating et al., 2008), and in another study the c9,t11 CLA isomer $(60 \mu M)$ was able to reduce the caspase-3 activity, thus decreasing apoptosis rate, in bovine aortic endothelial cells (Lai et al., 2005), suggesting the hypothesis that the effects of CLA are cell-specific.

For all the following experiments, the working concentration of CLA was set at $50 \mu M$. This concentration of CLA was selected after preliminary studies that were carried out by co-incubating the monocytes with different concentrations of CLA isomers, demonstrating that no differences occurred in modulation of apoptosis rate using concentrations ranging from 10 to $500 \mu M$. The use of a concentration of $50 \mu \mathrm{M}$ was set to compare the present results with others from previous studies that used the same CLA concentration (Basiricò et al., 2015, 2017; Dipasquale et al., 2018). Indeed, the concentration of $50 \mu M$ is also close to physiological levels found in human sera (10 to $70 \mu M$; Basiricò et al., 2015). Moreover, positive effects when using $50 \mu M$ CLA, such as an improved redox status of bovine mammary cells (Basiricò et al., 2015) or atheroprotective properties in human monocytes, have been reported (McClelland et al., 2010).

To further investigate whether the effects reported were specific for CLA isomers and not related to an 
unspecific effect in response to treatment with FA, we compared the differential effects of linoleic acid as n-6 PUFA control and stearic acid as saturated acid, which is also the main FA found in some commercially available CLA supplements, on bovine monocyte apoptosis. We also incorporated a 50:50 mixture of both CLA isomers, because most of the animal studies reporting CLA benefits and commercially available CLA supplements use a mixture of these 2 isomers in roughly equal amounts (Song et al., 2005; Renner et al., 2012). The CLA mixture was the only treatment that caused a significant reduction in monocyte apoptosis compared with the vehicle (ethanol), an effect not observed with the individual CLA isomers.

In the following set of experiments, the ability of CLA isomers to modulate chemotaxis was studied. We did not observe any difference in monocytes' migration toward ZAS when treated with CLA isomers individually or in combination. These results differ from those previously reported in human monocytes, which demonstrated that CLA could modulate monocyte or macrophage chemotaxis by PPAR $\gamma$ activation and COX-2 inhibition, suggesting atheroprotective properties (McClelland et al., 2010). Intriguingly, a statistically significant reduction of chemotaxis was found when monocytes were co-incubated with stearic acid. These results contrast with previous reports in human monocytes, where stearic acid was found to have proinflammatory activity (Anderson et al., 2012).

In the final set of experiments, further defensive performance of monocytes in the inflammatory focus such as phagocytosis, killing capability, and respiratory burst were measured. Treating isolated monocytes with CLA has no effect on the phagocytic and killing capability of bovine monocytes. These findings are different than the reported effects of CLA on other species, including dogs and pigs, and other cellular targets such as polymorphonuclear cells, where the t10,c12 CLA isomer increased phagocytosis, either indirectly (Kang et al., 2007) or directly (Kang et al., 2009). No differences in the production of extracellular superoxide anion under normal conditions were found. On the contrary, treating cells with PMA, to mimic inflammatory conditions, upregulated ROS production in monocytes treated with the CLA mixture. These results are in agreement with those reported in human macrophages, where both c9,t11 and t10,c12 CLA isomers upregulated ROS synthesis, through a $\operatorname{PPAR} \gamma$-dependent mechanism (Stachowska et al., 2008). Remarkably, a similar effect of increasing ROS production was recently demonstrated in BME-UV1 mammary gland epithelial cells (Dipasquale et al., 2018). Moreover, the t10,c12 CLA isomer has already been shown to increase oxidative stress in human in vivo studies (Risérus et al.,
2002) and in canine polymorphonuclear cells (Kang and Yang, 2008; Kang et al., 2009).

\section{CONCLUSIONS}

Conjugated linoleic acid has been shown to present a wide range of beneficial properties for cow health, production, and welfare. However, its effects on immune cell responses and functionality have scarcely been addressed so far. This study demonstrates that CLA exerts an anti-apoptotic activity and can increase ROS production in an inflammatory in vitro model, suggesting that CLA may have relevant roles in modulating some in vitro monocyte immune functions. The present study provides evidence that the effects of each CLA isomer are different, and a combination of c9,t11 with t10,c12 CLA isomers induces synergic effects on at least 2 important monocyte immune functions: apoptosis and inflammation-induced respiratory burst. In addition to its isomer-dependent activity, effects of CLA are also strictly related to their cellular targets, as the effects observed on mammary gland and endothelial cell lines are different than those on immune-related cells such as monocytes. Several aspects of the potential immunomodulatory effects of n-6 FA are still elusive, particularly the molecular basis of the different mechanisms of action of CLA. Elucidation of these mechanisms would improve our understanding of the actions of CLA in experimental in vivo systems and determine its practical biological significance, supporting a more targeted use of CLA in dairy animal nutrition. Given the wide use of stearic acid in dairy animal nutrition, its immunomodulatory effect of reducing chemotaxis deserves to be further explored.

\section{ACKNOWLEDGMENTS}

This work was supported with grant agreement no. 765423-MANNA Project, which has received funding from the European Union's Horizon 2020 research and innovation program H2020-MSCA-ITN-2017-EJD: Marie Skłodowska-Curie Innovative Training Networks (European Joint Doctorate). We also acknowledge the support of Tiziana Brevini and her team of the Dipartimento di Scienze Veterinarie per la Salute, la Produzione Animale e la Sicurezza Alimentare the Università degli Studi di Milano, Italy, for her valuable support in the implementation of alternative cell culture systems. The present study was designed with the valuable support and suggestions of Umberto Bernabucci (Department of Agricultural and Forest Sciences, University of Viterbo, Italy), Arnulf Tröscher (BASF CHEMOVATOR, Ludwigshafen am Rhein, Germany), and Harald Hammon (Leibniz Institute for Farm Animal Biology, 
Dummerstorf, Germany). None of the authors of this paper has a financial or personal relationship with other people or organizations that could inappropriately influence or bias the content of the paper.

\section{REFERENCES}

Anderson, E. K., A. A. Hill, and A. H. Hasty. 2012. Stearic acid accumulation in macrophages induces toll-like receptor 4/2-independent inflammation leading to endoplasmic reticulum stress-mediated apoptosis. Arterioscler. Thromb. Vasc. Biol. 32:1687-1695. https://doi.org/10.1161/ATVBAHA.112.250142.

Basiricò, L., P. Morera, D. Dipasquale, A. Tröscher, and U. Bernabucci. 2017. Comparison between conjugated linoleic acid and essential fatty acids in preventing oxidative stress in bovine mammary epithelial cells. J. Dairy Sci. 100:2299-2309. https://doi.org/ 10.3168/jds.2016-11729.

Basiricò, L., P. Morera, D. Dipasquale, A. Tröscher, A. Serra, M. Mele, and U. Bernabucci. 2015. Conjugated linoleic acid isomers strongly improve the redox status of bovine mammary epithelial cells (BME-UV1). J. Dairy Sci. 98:7071-7082. https://doi.org/10 .3168/jds.2015-9787.

Bauman, D. E., L. H. Baumgard, B. A. Corl, and J. M. Griinari. 1999. Biosynthesis of conjugated linoleic acid in ruminants. Pages 1-14 in Proc. Am. Soc. Anim. Sci. , Indianapolis, IN. http://www.asas .org/jas/symposia/proceedings/0937.pdf.

Bhattacharya, A., J. Banu, M. Rahman, J. Causey, and G. Fernandes. 2006. Biological effects of conjugated linoleic acids in health and disease. J. Nutr. Biochem. 17:789-810. https://doi.org/10.1016/j .jnutbio.2006.02.009.

Ceciliani, F., V. Pocacqua, A. Miranda-Ribera, V. Bronzo, C. Lecchi, and P. Sartorelli. 2007. $\alpha_{1}$-Acid glycoprotein modulates apoptosis in bovine monocytes. Vet. Immunol. Immunopathol. 116:145-152. https://doi.org/10.1016/j.vetimm.2007.01.006.

Chávez-Galán, L., M.L. Olleros, D. Vesin, I. Garcia, and R.A. Harris. 2015. Much more than M1 and M2 macrophages, there are also $\mathrm{CD}_{169^{+}}$and $\mathrm{TCR}^{+}$macrophages. Front. Immunol. 6:263. https:// doi.org/10.3389/fimmu.2015.00263.

Churruca, I., A. Fernández-Quintela, and M. P. Portillo. 2009. Conjugated linoleic acid isomers: Differences in metabolism and biological effects. Biofactors 35:105-111. https://doi.org/10.1002/biof.13.

Csillik, Z., V. Faigl, M. Keresztes, E. Galamb, H. M. Hammon, A. Tröscher, H. Fébel, M. Kulcsár, F. Husvéth, G. Huszenicza, and W. R. Butler. 2017. Effect of pre- and postpartum supplementation with lipid-encapsulated conjugated linoleic acid on reproductive performance and the growth hormone-insulin-like growth factor-I axis in multiparous high-producing dairy cows. J. Dairy Sci. 100:5888-5898. https://doi.org/10.3168/jds.2016-12124.

Dänicke, S., J. Kowalczyk, L. Renner, J. Pappritz, U. Meyer, R. Kramer, E. M. Weber, S. Döll, J. Rehage, and G. Jahreis. 2012. Effects of conjugated linoleic acids fed to dairy cows during early gestation on hematological, immunological, and metabolic characteristics of cows and their calves. J. Dairy Sci. 95:3938-3953. https://doi.org/ 10.3168/jds.2011-4879.

de Veth, M. J., D. E. Bauman, W. Koch, G. E. Mann, A. M. Pfeiffer, and W. R. Butler. 2009. Efficacy of conjugated linoleic acid for improving reproduction: A multi-study analysis in early-lactation dairy cows. J. Dairy Sci. 92:2662-2669. https://doi.org/10.3168/ jds.2008-1845.

Dilda, F., G. Gioia, L. Pisani, L. Restelli, C. Lecchi, F. Albonico, V. Bronzo, M. Mortarino, and F. Ceciliani. 2012. Escherichia coli lipopolysaccharides and Staphylococcus aureus enterotoxin B differentially modulate inflammatory microRNAs in bovine monocytes. Vet. J. (London) 192:514-516. https://doi.org/10.1016/j.tvjl.2011 .08.018.

Dipasquale, D., L. Basiricò, P. Morera, R. Primi, A. Tröscher, and U. Bernabucci. 2018. Anti-inflammatory effects of conjugated linoleic acid isomers and essential fatty acids in bovine mammary epithelial cells. Animal 12:2108-2114. https://doi.org/10.1017/ S1751731117003676.

Feig, C., and M. E. Peter. 2007. How apoptosis got the immune system in shape. Eur. J. Immunol. 37(Suppl. 1):S61-S70. https://doi.org/ 10.1002/eji.200737462.

Fritsche, J., R. Rickert, H. Steinhart, M. P. Yurawecz, M. M. Mossoba, N. Sehat, J. A. G. Roach, J. K. G. Kramer, and Y. Ku. 1999. Conjugated linoleic acid (CLA) isomers: Formation, analysis, amounts in foods, and dietary intake. Lipid 101:272-276. https: // doi.org/10.1002/(SICI)1521-4133(199908)101:8<272::AIDLIPI272>3.0.CO;2-W.

Galamb, E., V. Faigl, M. Keresztes, Z. Csillik, A. Tröscher, P. Elek, M. Kulcsár, G. Huszenicza, H. Fébel, and F. Husvéth. 2017. Effect of pre- and post-partum supplementation with lipid-encapsulated conjugated linoleic acid on milk yield and metabolic status in multiparous high-producing dairy cows. J. Anim. Physiol. Anim. Nutr. (Berl.) 101:1026-1035. https://doi.org/10.1111/jpn.12544.

Griinari, J. M., B. A. Corl, S. H. Lacy, P. Y. Chouinard, K. V. V. Nurmela, and D. E. Bauman. 2000. Conjugated linoleic acid is synthesized endogenously in lactating dairy cows by $\Delta 9$-desaturase. J. Nutr. 130:2285-2291. https://doi.org/10.1093/jn/130.9.2285.

Hussen, J., and H.-J. Schuberth. 2017. Heterogeneity of bovine peripheral blood monocytes. Front. Immunol. 8:1875. https://doi.org/10 .3389/fimmu.2017.01875.

Kang, J. H., G. S. Lee, E. B. Jeung, and M. P. Yang. 2007. Trans-10, cis-12-conjugated linoleic acid increases phagocytosis of porcine peripheral blood polymorphonuclear cells in vitro. Br. J. Nutr. 97:117-125. https://doi.org/10.1017/S0007114507280584.

Kang, J. H., G. S. Lee, E. B. Jeung, and M. P. Yang. 2009. Trans-10, cis-12 conjugated linoleic acid modulates phagocytic responses of canine peripheral blood polymorphonuclear neutrophilic leukocytes exposed to Clostridium difficile toxin B. Vet. Immunol. Immunopathol. 130:178-186. https://doi.org/10.1016/j.vetimm.2009 .02 .005 .

Kang, J.-H., and M.-P. Yang. 2008. In vitro evaluation of the effect of trans-10, cis-12 conjugated linoleic acid on phagocytosis by canine peripheral blood polymorphonuclear neutrophilic leukocytes exposed to methylprednisolone sodium succinate. Am. J. Vet. Res. 69:494-500. https://doi.org/10.2460/ajvr.69.4.494.

Kay, J. K., J. R. Roche, E. S. Kolver, N. A. Thomson, and L. H. Baumgard. 2005. A comparison between feeding systems (pasture and TMR) and the effect of vitamin E supplementation on plasma and milk fatty acid profiles in dairy cows. J. Dairy Res. 72:322332. https://doi.org/10.1017/S0022029905000944.

Keating, A. F., F. Q. Zhao, K. A. Finucane, D. R. Glimm, and J. J. Kennelly. 2008. Effect of conjugated linoleic acid on bovine mammary cell growth, apoptosis and stearoyl Co-A desaturase gene expression. Domest. Anim. Endocrinol. 34:284-292. https://doi.org/ 10.1016/j.domaniend.2007.08.005.

Lahlou, M. N., R. Kanneganti, L. J. Massingill, G. A. Broderick, Y. Park, M. W. Pariza, J. D. Ferguson, and Z. Wu. 2014. Grazing increases the concentration of CLA in dairy cow milk. Animal 8:1191-1200. https://doi.org/10.1017/S1751731114000998.

Lai, K. L., A. P. Torres-Duarte, and J. Y. Vanderhoek. 2005. 9-trans,11trans-CLA: Antiproliferative and proapoptotic effects on bovine endothelial cells. Lipids 40:1107-1116. https://doi.org/10.1007/ s11745-005-1474-1.

Lecchi, C., F. Ceciliani, S. Bernasconi, F. Franciosi, V. Bronzo, and P. Sartorelli. 2008. Bovine alpha-1 acid glycoprotein can reduce the chemotaxis of bovine monocytes and modulate CD18 expression. Vet. Res. 39:50. https://doi.org/10.1051/vetres:2008027.

Lecchi, C., G. Invernizzi, A. Agazzi, M. Ferroni, L.F. Pisani, G. Savoini, and F. Ceciliani. 2011. In vitro modulation of caprine monocyte immune functions by $\omega-3$ polyunsaturated fatty acids. Vet. J. (London) 189:353-355. https://doi.org/10.1016/j.tvjl.2010 .09.001.

Lecchi, C., N. Rota, A. Vitali, F. Ceciliani, and N. Lacetera. 2016. In vitro assessment of the effects of temperature on phagocytosis, reactive oxygen species production and apoptosis in bovine polymorphonuclear cells. Vet. Immunol. Immunopathol. 182:89-94. https:/ /doi.org/10.1016/j.vetimm.2016.10.007. 
Lecchi, C., A. Scarafoni, V. Bronzo, P. A. Martino, A. Cavallini, P. Sartorelli, and F. Ceciliani. 2013. $\alpha_{1}$-Acid glycoprotein modulates phagocytosis and killing of Escherichia coli by bovine polymorphonuclear leucocytes and monocytes. Vet. J. 196:47-51. https://doi .org/10.1016/j.tvjl.2012.07.022.

McClelland, S., C. Cox, R. O'Connor, M. de Gaetano, C. McCarthy, L. Cryan, D. Fitzgerald, and O. Belton. 2010. Conjugated linoleic acid suppresses the migratory and inflammatory phenotype of the monocyte/macrophage cell. Atherosclerosis 211:96-102. https:// doi.org/10.1016/j.atherosclerosis.2010.02.003.

Ochoa, J. J., A. J. Farquharson, I. Grant, L. E. Moffat, S. D. Heys, and K. W. J. Wahle. 2004. Conjugated linoleic acids (CLAs) decrease prostate cancer cell proliferation: Different molecular mechanisms for cis-9, trans-11, and trans-10 cis-12 isomers. Carcinogenesis 25:1185-1191. https://doi.org/10.1093/carcin/bgh116.

Pariza, M. W., Y. Park, and M. E. Cook. 2001. The biologically active isomers of conjugated linoleic acid. Prog. Lipid Res. 40:283-298. https://doi.org/10.1016/S0163-7827(01)00008-X.

Perfield, J. W. II, A. L. Lock, J. M. Griinari, A. Sæbø, P. Delmonte, D. A. Dwyer, and D. E. Bauman. 2007. Trans-9,cis-11 conjugated linoleic acid reduces milk fat synthesis in lactating dairy cows. J. Dairy Sci. 90:2211-2218. https://doi.org/10.3168/jds.2006-745.

Renner, L., S. Kersten, A. Duevel, H. J. Schuberth, and S. Dänicke. 2013. Effects of cis-9,trans-11 and trans-10,cis-12 conjugated linoleic acid, linoleic acid, phytanic acid and the combination of various fatty acids on proliferation and cytokine expression of bovine peripheral blood mononuclear cells. Nutrients 5:2667-2683. https: //doi.org/10.3390/nu5072667.

Renner, L., J. Pappritz, R. Kramer, S. Kersten, G. Jahreis, and S. Dänicke. 2012. Fatty acid profile and proliferation of bovine blood mononuclear cells after conjugated linoleic acid supplementation. Lipids Health Dis. 11:63. https://doi.org/10.1186/1476-511X-11 -63 .
Risérus, U., S. Basu, S. Jovinge, G. N. Fredrikson, J. Ärnlöv, and B. Vessby. 2002. Supplementation with conjugated linoleic acid causes isomer-dependent oxidative stress and elevated C-reactive protein: A potential link to fatty acid-induced insulin resistance. Circulation 106:1925-1929. https://doi.org/10.1161/01.CIR.0000033589 .15413 .48 .

Selberg, K. T., A. C. Lowe, C. R. Staples, N. D. Luchini, and L. Badinga. 2004. Production and metabolic responses of periparturient Holstein cows to dietary conjugated linoleic acid and trans-octadecenoic acids. J. Dairy Sci. 87:158-168. https://doi.org/10.3168/ jds.S0022-0302(04)73153-7.

Song, H.-J., I. Grant, D. Rotondo, I. Mohede, N. Sattar, S. D. Heys, and K. W. J. Wahle. 2005. Effect of CLA supplementation on immune function in young healthy volunteers. Eur. J. Clin. Nutr. 59:508-517. https://doi.org/10.1038/sj.ejcn.1602102.

Sordillo, L. M. 2016. Nutritional strategies to optimize dairy cattle immunity. J. Dairy Sci. 99:4967-4982. https://doi.org/10.3168/jds .2015-10354.

Stachowska, E., M. Baśkiewicz-Masiuk, V. Dziedziejko, I. Gutowska, I. Baranowska-Bosiacka, M. Marchlewicz, B. Dołegowska, B. Wiszniewska, B. Machaliński, and D. Chlubek. 2008. Conjugated linoleic acid increases intracellular ROS synthesis and oxygenation of arachidonic acid in macrophages. Nutrition 24:187-199. https:/ /doi.org/10.1016/j.nut.2007.10.018.

Viladomiu, M., R. Hontecillas, and J. Bassaganya-Riera. 2016. Modulation of inflammation and immunity by dietary conjugated linoleic acid. Eur. J. Pharmacol. 785:87-95. https://doi.org/10.1016/ j.ejphar.2015.03.095.

Wang, L. S., Y. W. Huang, S. Liu, P. Yan, and Y. C. Lin. 2008. Conjugated linoleic acid induces apoptosis through estrogen receptor alpha in human breast tissue. BMC Cancer 8:208. https://doi.org/ 10.1186/1471-2407-8-208. 